\title{
A Study of Automatic Welding Control System for Building Steel
}

\author{
Hongguo Sun \\ School of Electrical Engineering, Yancheng Institute of Technology, \\ Yancheng 224051, PR China \\ sunhg@ycit.edu.cn
}

\begin{abstract}
This paper introduces a kind of building steel automatic welding system and it adopts submerged arc welding to complete the welding. There are four processes in the welding, including arc, melting, extrusion and insulation, which are completed by the single chip C8051F021.To ensure the arc and melting processes are accomplished accurately, the voltage and current double closed loop is used to determine whether the arc ignition is success and the melting time are estimated by arc energy accumulation from real-time judgment. Using power devices IGBT, inverse variable technology and programming logic devices (PLD) to constitute a new type of arc welding inverse variable power source. Programming on the PLD with VHDL language and get PWM's simulation waveform. The results show that the PWM waveform designed by VHDL has high control precision, flexible control, able to adjust the power switch tube dead time, effectively protect switch safety work, and improve the efficiency of welding.
\end{abstract}

Keywords: building steel; single chip; welding system; arc welding power

\section{Introduction}

The welding system is developed based on domestic AC $(50 \mathrm{~Hz})$ automatic welding machine, which consists of the intelligent control box, welding head and the inverter welding power. The system uses C8051F021 microcontroller and programmable logic device (CPLD) to replace the original discrete components of electronic control system and append current testing on the basis of original voltage testing to achieve intelligent arc judgment [1-5]. By using the energy accumulation to control the amount of melting instead of controlled by the time, namely excessive or inadequate of the melting. It uses the high frequency inverter that is controlled by PWM, rectified to DC welding power to replace the $50 \mathrm{~Hz}$ welding power supply with $50 \mathrm{~Hz}$. The volume and weight of arc welding power source is greatly reduced and with DC welding instead of AC welding [6-10], it avoids the environmental pollution caused by the high frequency welding. The whole process of the system includesarc, melting, extrusion and insulation and the whole process is intelligent automatic. The total system block diagram as shown in Figure 1. 


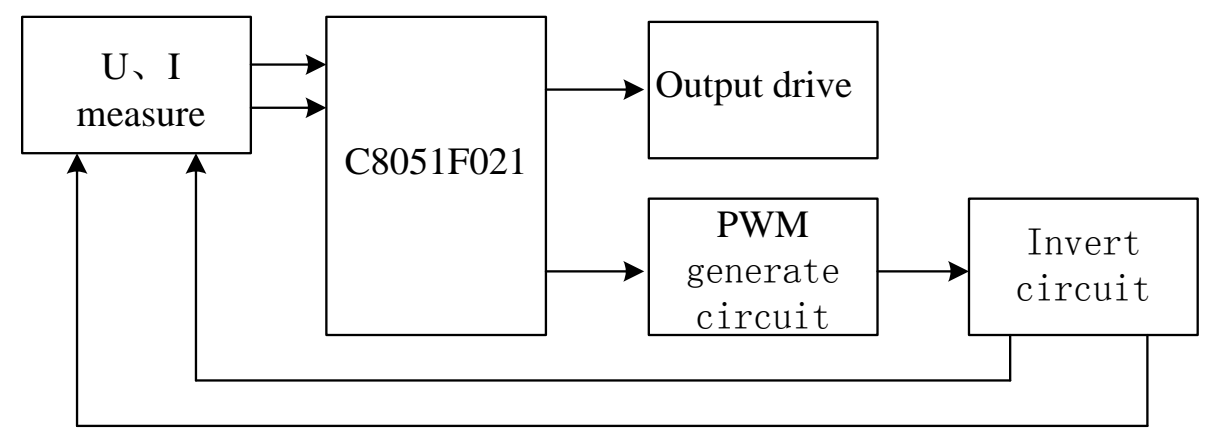

Fig.1 The block diagram of system

\section{Structure and Principle of Control System}

The system selects C8051F021 microcontroller as CPU core. The C8051F021 devices are fully integrated mixed-signal System-on-a-Chip MCUs with 32 digital I/O pins, Highlighted features are high-Speed pipelined 8051-compatible CIP-51 microcontroller core (up to 25 MIPS), and true 12-bit $100 \mathrm{ksps}$ 8-channel ADC with PGA and analog multiplexer, and On-chip Watchdog Timer, VDD Monitor, and Temperature Sensor. All analog and digital peripherals are enabled/disabled and configured by user firmware. The FLASH memory can be reprogrammed even in-circuit, providing non-volatile data storage, and also allowing field upgrades of the 8051 firmware.

On-board JTAG debug circuitry allows non-intrusive (uses no on-chip resources), full speed, in-circuit debugging using the production MCU installed in the final application. This debug system supports inspection and modification of memory and registers, setting breakpoints, watch points, single stepping, run and halt commands. All analog and digital peripherals are fully functional while debugging using JTAG.

\subsection{Measuring circuit}

The measurement object of this system is the output voltage and current from arc welding power source.

First, measurement of DC welding current. With the wide application of inverter technology, the working frequency of arc welding power source is also rising, but the high-frequency alternating current as directly used for welding has an adverse effect on the environment and the people around, plus DC welding performance than the AC welding and it doesn't have arc interruption phenomenon, so the DC arc welding has been widely applied. However, the DC current no alternating current that is convenient to test, especially the high current measurement, it uses shunts to change the 750A DC current into the voltage of $75 \mathrm{mV}$ voltage. If transferring the voltage directly to the input end of ADC microcontroller, the effect and anti-interference ability are poor, and thus in the voltage of $75 \mathrm{mV}$ and single chip microcomputer the ADC terminal of an OPAMP posed by the in-phase proportion circuit, turning the $75 \mathrm{mV}$ into a $5 \mathrm{~V}$ voltage, suitable for $\mathrm{A} / \mathrm{D}$ conversion requirements, at the same time, improve the anti-interference ability. 
Second, measurement of DC voltage. It uses of optocoupler isolation transmission circuit composed of double optical coupler, dual operational amplifier, as shown in Figure 2, Dual OP AMP two voltage follower, transmission characteristic of $\mathrm{T}_{4}, \mathrm{~T}_{5}$ current through the circuit symmetry and feedback principle, can compensate their original nonlinear, the linear error of the circuit is not more than $0.2 \%$. $\mathrm{T} 4$ and $\mathrm{A} 1$ as the input stage, $\mathrm{T}_{5}$ and $\mathrm{A} 2$ as the output stage circuit, transmission coefficient for $\mathrm{K}=\mathrm{R}_{25} /\left(\mathrm{R}_{23}+\mathrm{R}_{\mathrm{W} 1}\right)$, the reasonable selection of two resistance value can get the appropriate voltage.

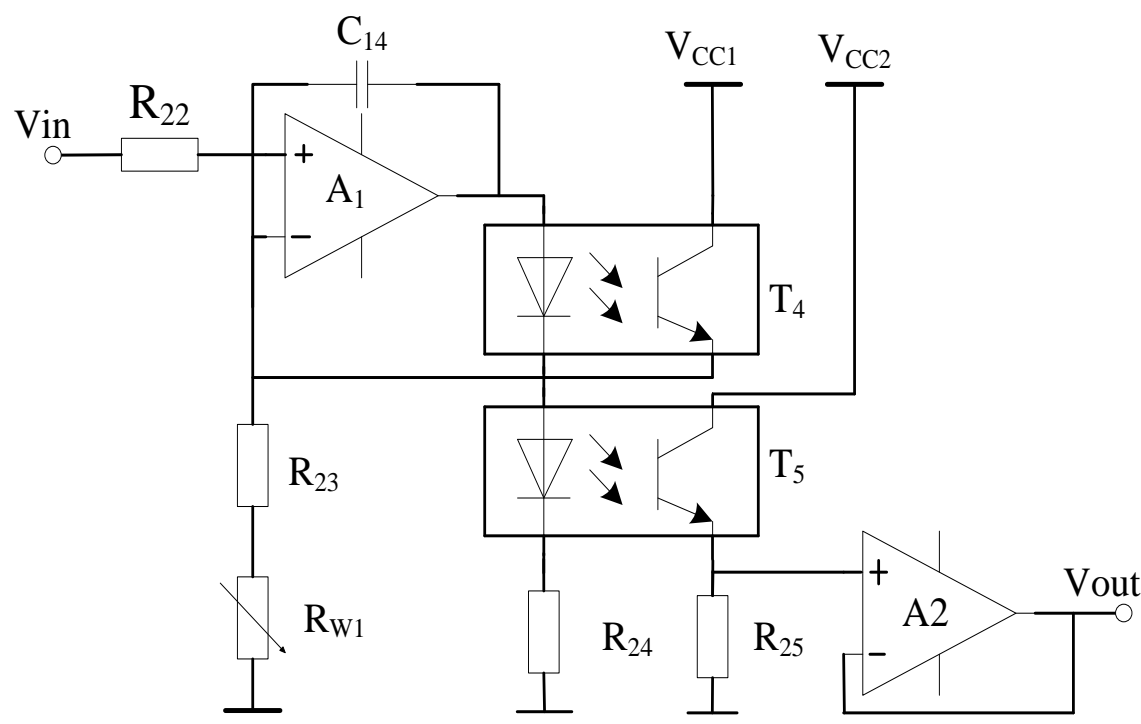

Figure 2. The measurement of DC voltage

\subsection{Output driver circuit}

The rise and fall of the welding head is controlled by the driving circuit welding head fixture on the servo motor to complete. Drive circuit, a total of three, its structure is similar, as shown in Figure 3, only draw one. Low-level effective way to drive the load is proposed, which can avoid disoperation after the microcontroller reset, due to the single chip microcomputer P1 mouth on load capacity is limited (only can drive 4 LSTTL circuit), so add a inverter buffer after push light coupling, coupling effect of light is to prevent the backward channel interference with single chip microcomputer, R4 for current limiting resistor. P1.0 control relay drive contactor lines), on its control relay lines parallel a light-emitting diode is used as the indicator, P1.1 and P1.2 control relay drive servo motor forward and inversion, and realize the rise and fall of the welding head clamp, $\mathrm{KF}$ and $\mathrm{KZ}$ can realize self-locking. Switch S1 S3 are manual buttons, their roles are giving power to electric welding machine, welding head respectively the rise and fall of the jig. 

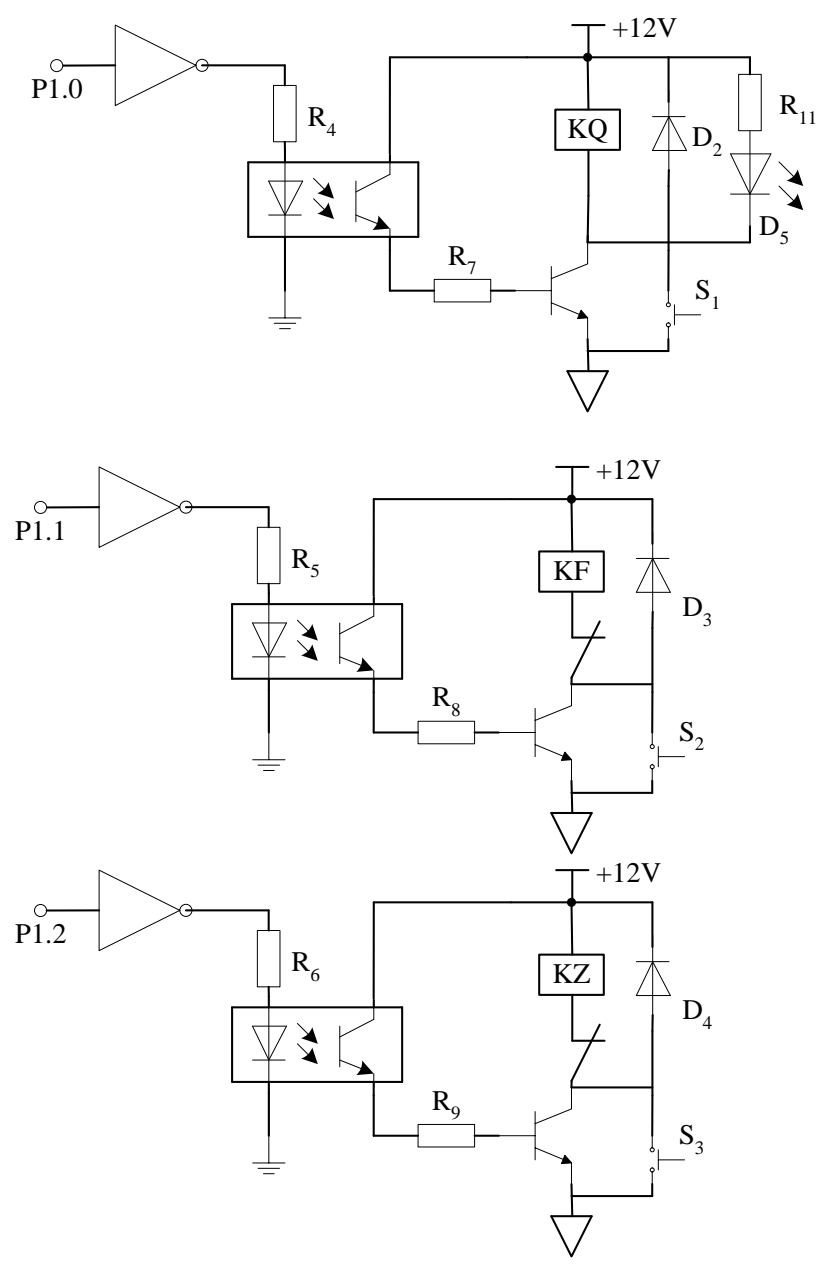

Figure 3. The drive circuit of output

\section{Composition and Principles of Arc Welding Power Source Circuit}

As we all know, according to the sine wave analysis of transformer, it has the following basic formula:

$$
\mathrm{U}=4.44 \mathrm{fNSBm}
$$

Where $\mathrm{S}$ is iron core cross-sectional area, $\mathrm{Bm}$ is the maximum value of the magnetic induction intensity.

Obviously, the weight and volume of the transformer are associated with NS, and NS has a direct relationship with f.From the above formula, we can obtain:

$$
\mathrm{NS}=\mathrm{U} / 4.44 \mathrm{fBm}
$$

Where the $\mathrm{Bm}$ is a certain value, if the frequency from the frequency increased to $20 \mathrm{KHz}$, then the product number of winding turns and the sectional area of the iron core on the decrease, and the main transformer for arc welding inverter weight is from $1 / 3$ to $2 / 3$, therefore, it can make the weight, volume decreased significantly, meanwhile, copper and iron power loss with significantly reduced need material is greatly reduced. 


\subsection{Composition of the high-frequency inverter}

The high frequency inverter circuit with half-bridge inverter circuit [11-15], as shown in Figure 4. High frequency inverter circuit of input is the DC voltage U1 rectifier and filter, the circuit is composed of two identical capacity voltage capacitors C1, C2 and IGBT two consistent models of VT1, VT2 composed of a bridge. Two ends of the input supply voltage $\mathrm{U} 1$ is applied to bridge a diagonal a, B, and the primary winding high frequency transformer TR is connected to the bridge at both ends of the other diagonal points $\mathrm{c}, \mathrm{D}$, the secondary winding is a central tapped full-wave rectifier circuit. VT1, VT2 alternate conduction, complete the process of DC-AC inverter, the inverter frequency is $20 \mathrm{kHz}$. The output of the inverter through the diode VD1, VD2 composed of a full-wave rectifying circuit and a DC output filter inductance L, and then changed into DC, for welding. VD1, VD2 fast recovery diode. RW adjustable resistor and a fixed resistor divider circuit, so that after adjustment can get the appropriate voltage, so as to supply voltage measurement circuit [16-18].

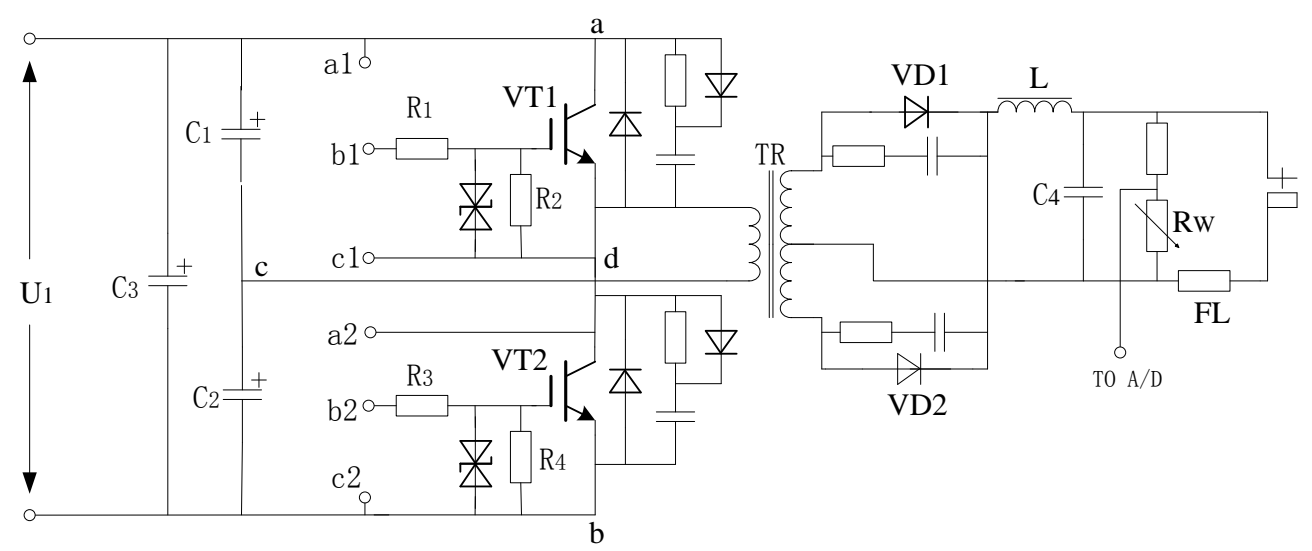

Figure 4. The circuit schematic diagram of welding inverter

This circuit is a half-bridge inverter circuit, a switching device, the switching voltage is not high, the drive is simple, low cost, the output frequency and voltage of the same bridge arm switch frequency, transformer utilization rate than the single end output high, easy to higher output power, while the relative full-bridge mode, the circuit structure is simple, the debugging relatively easy, it has one of the biggest advantages, namely the unbalance resistance ability is very strong.

\subsection{Principle and Implementation of PWM pulse forming}

At present, inverter power often use special chip PWM waveform generation such as TL494, SG3525, and the regulation of PWM waveform of the width of the feedback signal, so as to obtain stable output [19-21]. When the control circuit design, is a relatively independent system, regulate, control mode cannot be changed, overall coordination functions of the system error. In recent years, the inverter system controlled by microcomputer is mainly based on MCU or DSP (digital signal processor) control. Using single chip microcomputer system if the use of timer PWM, due to disruption of the characteristics, the width of output PWM is prone to change, thus affecting the accuracy of output voltage. Such as MCS51 series, interrupt response for 3 8 machine cycle, with the $6 \mathrm{MHz}$ oscillator, a machine cycle is $2 \mu \mathrm{s}$, the inverter frequency is $20 \mathrm{kHz}$, the work cycle of $50 \mu \mathrm{s}$, the error range is $12 \% \sim 32 \%$; in addition, the real-time system is poor, so MCU systems generally need 
produced by PWM chip, SCM is mainly used for work and output coordination system display. Real-time system for DSP good, but poor flexibility, general DSP system overall control, coordinate the performance is not very good, but the DSP development process is more complex and development tools are expensive.

Generally, the main circuit consists of high frequency inverter power supply frequency is $20 \mathrm{kHz}$ by IGBT, the work period is $50000 \mathrm{~ns}$. Because the reverse diode power switching devices in parallel reverse recovery time, two output pulse must keep the dead time is certain, in dead time, the two bridge arm two switching devices are not conducted, so as to ensure the safe operation of power devices and circuits, for the fourth generation of IGBT, considering the dead time requirements, dual PWM pulse duty ratio, the maximum value is $80 \%$, so the single PWM pulse that is each bridge arm IGBT the biggest turn-on time: $50000 \times$ $0.4=20000 \mathrm{~ns}$, dead time between each PWM is: $50000 \times 0.1=5000 \mathrm{~ns}$. If the CPLD/FPGA external $20 \mathrm{MHz}$ clock cycle is $50 \mathrm{~ns}$, the frequency of cycle frequency $20 \mathrm{kHz}$ inverse power supply of $50000 \mathrm{~ns}$, a total of 1000 clock cycles, therefore, dual PWM duty cycle regulation accuracy is $0.2 \%$, namely each change the 1 clock cycle, pulse width two-way change the 2 period, the duty cycle is the rate of change: $2 / 1000=0.2 \%$. So, using CPLD/FPGA inverter system can be easily adjusted by changing the external crystal oscillator frequency PWM duty cycle adjustment precision to meet the specific requirements of different systems and reduce the equipment costs [22-27].

The output voltage, current digital arc welding inverter power source sampling after A/D conversion into the SCM, SCM control algorithm to calculate the pulse width of PWM, and send it to CPLD. Then, based on MCU CPLD into value generates a phase difference of 1800, two IGBT with dead time and the minimum pulse width of the drive pulse limit. In this way, the driving pulse duty ratio pulse width with single-chip microcomputer to calculate and output the value corresponding changes. At the same time CPLD sends control signals back to the SCM collaborative relationship, impulse control and PWM to coordinate the current, voltage sampling. In order to facilitate the overload of digital welding machine monitor and control measures can be taken to protect the effective time, digital PWM chip designed for overcurrent and undervoltage conditions, blockade of PWM pulse output function. OC for overcurrent protection, under-voltage protection control terminal for UV, en for PWM pulse output enable control terminal, module pulse width data input, data bus microcontroller connected to; CLK signal as the clock signal input end, it is the entire digital PWM chip control reference or a rhythm, play a decisive effect on the precision and stability of output. Pwm1 and pwm2 PWM pulse output, the output phase difference of two output 1800 driving pulse. SYN is the output control end. The simulation waveform diagram as shown in Figure 5 .

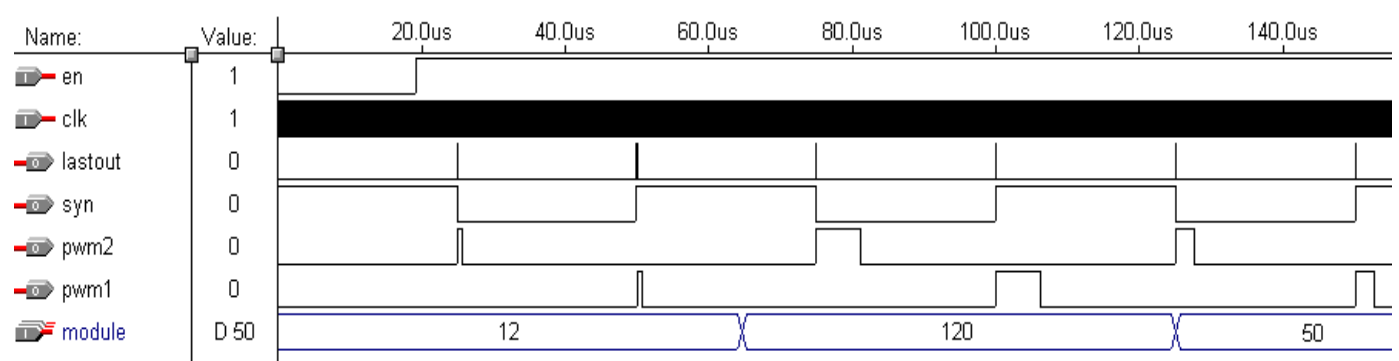

Figure 5. Emulation waveforms of PWM

From the simulation waveforms can be seen: the cycle of the output waveform is $50 \mu \mathrm{s}$; when the microcontroller output data values are not the same, the width of the PWM is not 
the same, graph has output data were $12,120,50$, a pulse width corresponding to different; the top behavior enable terminal, in $20 \mu \mathrm{s}$, enable is low, data transmission cannot be single to the programmable logic device, no output pulse; SYN the output of collaborative signal, feedback to the microcontroller as the synchronization signal.

\section{Compilation of System Software}

The system uses C8051F021 as the core of control system, external keyboard, and display circuit. The keyboard is used for different welding bar diameter $(\varphi 8 \mathrm{~mm}$ to $\varphi 40 \mathrm{~mm})$ was set up, the display circuit to display welding bar diameter and the welding voltage. These external expansion circuit and MCU interface is simple, needs no additional device.

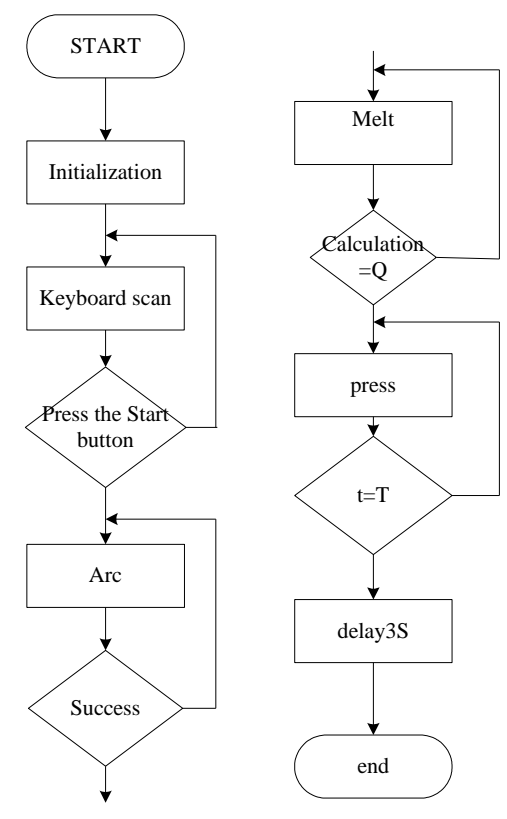

\section{Figure 6. The flowchart of software}

In order to facilitate debugging, in the design of system program, the "modular" form, the main program flow chart shown in Figure 6, consists of keyboard scanning, look-up table, number system conversion, A/D conversion, delay, alarm, working procedure subprogram, the working procedure is the core, the other is the subroutine the. The system uses the voltage, current double closed-loop, combined with software processing as the basis to judge arc is successful and melting amount is modest, to solve the existing problems in the current product. Based on the measured voltage, the current value of the first arc guiding system is judged, excessive voltage, current is too small, control fixture decline; voltage is too small, the current is too large, the control clamp rises; voltage equal to zero or current tends to infinity, the short-circuit phenomenon; only the voltage is not current, the arcing phenomenon; only when the voltage and current at the same time reaches a predetermined value (voltage range of $10 \sim 30 \mathrm{~V}$, current of $100 \sim 400 \mathrm{~A}$ ), the system that arc is successful. Arc is successful, also need to be accumulated on heat equivalent welding burning, and at any time and the standard value, once the equal is transferred to the next procedure, extrusion, and heat preservation is a time to complete, relatively simple. 
The standard value is determined by using electric arc steelmaking technology, mainly consider from three aspects [28]:

First, determinate the effective heating power of electric arc welding. If the welding current is I (A), arc voltage is $\mathrm{U}(\mathrm{V})$, the effective heating power of electric arc welding to the work piece is as follows:

$$
\mathrm{q}=\eta \mathrm{IU}(\mathrm{W})
$$

Where $\eta$ is welding thermal efficiency, it reflects the effective utilization of heat energy in the welding process. The automatic submerged arc welding heat is difficult to spread, so the value of $\eta$ is higher, ranging from 0.9 to 0.99 .

Second, determine the types of temperature field. Welding temperature field can be divided into three types: three-dimensional heat transfer, two-dimensional heat transfer and one-dimensional heat transfer. Reinforced butt welding is a surface heat source that distribute equally in cross section and the temperature field that transfer heat along the axial direction of the one-dimensional. Due to the strong thermal conductivity of metal, heat energy can transfer into the internal of work piece from the heat supply quickly and make the temperature field becomes small. In order to ensure a sufficient supply of molten pool size and penetration when welding the steel, it should use the large standard parameters (the effective heat efficiency of welding heat source and welding speed). Temperature follows exponential distribution along axial of reinforcing steel, but the temperature is more concentrated in close quarters, so heat mainly concentrated in this region and it can be approximated as a linear relationship. The range is 0 to $5 \mathrm{~cm}$, the temperature is steel melting temperature, $\mathrm{T} \sim 50^{\circ} \mathrm{C}$.

Third, determine the heat required to melt. This part of the energy is depended on the components of steel and the different chemical compositions will result in different melting point. The method to obtain approximate value of steel liquid melting point:

$$
T_{\text {melt }}=1539-\sum \Delta t x \%{ }^{\circ} \mathrm{C}
$$

Where 1539 as the melting point of pure iron, $\Delta t$ is the decreasing value of melting point when some elements content in the steel increased $1 \%, \mathrm{x} \%$ is the percentage composition of the element. For example: the carbon content of the steel is $0.5 \%$, the carbon of the melting point is $1480^{\circ} \mathrm{C}$. The melting points of the different carbon content in steel are given Table 1 .

Table 1. The melting points of the different carbon content in steel

\begin{tabular}{|c|c|c|c|c|}
\hline the carbon content in steel, $\%$ & 0.5 & 1.0 & 1.5 & 2.0 \\
\hline melting point, ${ }^{\circ} \mathrm{C}$ & 1480 & 1460 & 1435 & 1400 \\
\hline
\end{tabular}

Mean specific heat of carbon steel is $0.7 \times 103 \mathrm{~J} / \mathrm{kg} \cdot{ }^{\circ} \mathrm{C}$, the heat of fusion is $2.73 \times 105$ $\mathrm{J} / \mathrm{kg}$, then the heat required to melt the steel:

$$
Q_{1}=m_{1} c \Delta t_{1}+m_{1} j
$$

Where $\mathrm{m} 1$ is the mass of molten steel, which is determined by the diameter and length of steel, length value is between 12 and $16 \mathrm{~mm}$; $\mathrm{c}$ is specific heat, $\Delta \mathrm{t} 1$ is changes in temperature and it is the difference between $T_{\text {melt }}$ and the surrounding environment temperature, $\Delta \mathrm{t} 1=$ $\mathrm{T}_{\text {melt }}-\mathrm{T}_{\text {environment }} ; \quad \mathrm{j}$ is the heat of fusion. 
In addition to the heat required for melting, another part of the heat needs to be considered, the temperature change of the remaining steel:

$$
Q_{2}=m_{2} c \Delta t_{2}
$$

Where $\mathrm{m} 2$ is the mass of steel that temperature changes but no melting, $\Delta \mathrm{t} 2$ is the changes in temperature, $\Delta \mathrm{t} 2=\left(\mathrm{T}_{\text {melt }}+50\right) / 2$.

Adding the two parts heat to calculate the total heat absorption of the steel bar, and then divided by the welding heat efficiency $\eta$ to obtain the standard $Q$. The standard $Q$ is preset in the program. When the system is working, the heat of arc is accumulated, $\mathrm{Q}_{\mathrm{in}}=\mathrm{UIt}$, and to compare $\mathrm{Q}_{\text {in }}$ and $\mathrm{Q}$ at all times, when $\mathrm{Q}_{\text {in }}$ is greater than or equal to $\mathrm{Q}$, it will go to the next step.

\section{Conclusion}

The system utilizes a single chip to control four process of structural steel butt welding, using CPLD to generate PWM pulse waveform, through the improvement of the original system, the present system can not only realize the function of automatic welding system, easy to modify, accurate control, flexible, reduces operator many workload, improve the quality of welding, greatly improve welding performance, but also can save steel (the original system of welding melting was about $20 \mathrm{~mm}$, the present system can be controlled in $12 \sim 16$ $\mathrm{mm}$ ), to improve the welding efficiency.

\section{References}

[1] M. Sahin, "Characterization of properties in plastically deformed austenitic-stainless steels joined by friction welding", Materials and Design, vol. 30, no. 135, (2009).

[2] Y. Peng, K. H. Wang, Q. Zhou, Y. J. Wang and P. F. Fu, "Beam quality test technology and devices of electron beam welding", Vacuum, vol. 86, no. 26, (2011).

[3] K. Faes, A. Dhooge, P. De Baets, E. Van Der Donckt and W. De Waele, "Parameter optimization for automatic pipeline girth welding using a new friction welding method", Materials and Design, vol. 30, no. 581, (2009).

[4] H. -C. Chen, A. J. Pinkerton, L. Li, Z. Liu and A. T. Mistry, "Gap-free fibre laser welding of Zn-coated steel on $\mathrm{Al}$ alloy for light-weight automotive applications", Materials and Design, vol. 32, no. 495, (2011).

[5] D. Jaroslav, N. Daniel, "TriP soft-switching PS-PWM DC-DC converter for full-load range applications", IEEE Transactions on Industrial Electronics, vol. 57, no. 2807, (2010).

[6] B. R. Lin, H. K. Chiang and C. C. Chen, "Analysis and implementation of a ZVS-PWM converter with series-connected transformers", IEEE Transactions on Circuits and Systems, vol. 54, no. 917, (2007).

[7] H. F. Xiao and S. J. Xie, "A ZVS Bidirectional DC-DC converter with phase-shift plus PWM control scheme", IEEE Transactions On Power Electronics, vol. 23, no. 813, (2008).

[8] C. Wu, X. B. Ruan and R. R. Zhang, "A novel zero-voltage-switching PWM full bridge converter", IEEE Transactions on power Electronics, vol. 23, no. 793, (2008).

[9] F. Vollertsen and C. Thomy, "Welding with fibre lasers from 200 to $17000 \mathrm{~W}$. In: ICALEO 2005 - 24th international congress on applications of laser and electro-optics", (2005), pp. 254-263, Miami, FL, USA.

[10] F. Vollertsen, "Developments and trends in laser welding of sheet metal", Adv Mater Res, vol. 6-8, (2005), pp. 59-70.

[11] I. Miyamoto, T. Kosumi, P. Seo-jeong, H. Uragishi, K. Watanabe and T. Ooie, "Applications of single-mode fiber-lasers to novel micro welding", Proc SPIE, vol. 507, no. 5662, (2004).

[12] C. Thomy, T. Seefeld and F. Vollertsen, "High-power fibre lasers - applicationpotentials for welding of steel and aluminum sheet material”, Erlangen-Nuremberg (Germany): Trans Tech Publications Ltd., vol. 8, no. 171, (2005).

[13] A. Mathieu, R. Shabadi, A. Deschamps, M. Suery, S. Mattei, D. Grevey, et al., "Dissimilar material joining using laser (aluminum to steel using zinc-based filler wire)", Opt Laser Technol., vol. 39, no. 652, (2007).

[14] G. Tani, A. Ascari, G. Campana and A. Fortunato, "A study on shielding gas contamination in laser welding of non-ferrous alloys”, Appl Surf Sci., vol. 254, no. 904, (2007). 
[15] T. -Y. Kuo and Y. -D. Lin, "Effects of different shielding gases and power waveforms on penetration characteristics and porosity formation in laser welding of Inconel690 alloy", Mater Trans; vol. 48, no. 219, (2007).

[16] S. Katayama, H. Nagayama, M. Mizutani and Y. Kawahito, "Fibre laser welding of aluminum alloy", Weld Int; vol. 23, no. 744, (2009).

[17] C. T. Kwok, S. L. Fong, F. T. Cheng and H. C. Man, "Pitting and galvanic corrosion behavior of laser-welded stainless steels", J Mater Process Technol; vol. 176, no. 168, (2006).

[18] S. Yan, Z. Hong, T. Watanabe and T. Jingguo, "CW/PW dual-beam YAG laser welding of steel/aluminum alloy sheets", Opt Lasers Eng; vol. 48, no. 732, (2010).

[19] M. J. Torkamany, S. Tahamtan and J. Sabbaghzadeh, "Dissimilar welding of carbon steel to 5754 aluminum alloy by Nd: YAG pulsed laser", Mater Des; vol. 31, no. 458, (2010).

[20] W. Chen, P. Ackerson and P. Molian, "CO2 laser welding of galvanized steel sheets using vent holes", Mater Des; vol. 30, no. 245, (2009).

[21] L. Agudo, D. Eyidi, C. H. Schmaranzer, E. Arenholz, N. Jank, J. Bruckner, et al., "Intermetallic FexAIy-phases in a steel/Al-alloy fusion weld", J Mater Sci; vol. 42, no. 4205, (2007).

[22] J. Z. Ding, W. M. Wang and J. Liu, "Design of digital PWM chip in digitization welding inverter by using VHDL", Transactions of the china welding institution, vol. 23, no. 47, (2002).

[23] H. Sun and J. Wu, "Plating pulse switching power based on a CPLD", Electrochimica Acta, vol. 105, no. 342, (2013).

[24] T. A. Palmer, J. W. Elmer, K. D. Nicklas and T. Mustaleski, "Transferring electron beam welding parameters using the enhanced modified faraday cup”, Welding Journal, vol. 86, no. 388, (2007).

[25] S. M. Qasim and S. A. Abbasi, "A new approach for arbitrary waveform generation using FPGA and orthogonal functions", In: 6th IEEE international workshop on system on chip for real time applications, IWSOC 2006, (2006) December 27-29. Cairo, Egypt.

[26] J. Kolouch, "Templates for CPLD and FPGA designs. Radioelektronika", In: RADIOELEKTRONIKA'09 19th international conference 2009; (2009) April 211-213.

[27] J. RoyChoudhury, T. P. Banerjee, A. Nathvani, R. B. R. Chowdhury and A. K. Bhattacharya, "Design methodology internal sub state observer using CPLD”, Nature \& Biologically Inspired Computing, NaBIC, vol. 40, no. 1636, (2009).

[28] C. Shen, "electric arc furnace steel-making technology and equipment", Metallurgical Industry Press, second edition, Beijing, (2010).

\section{Authors}

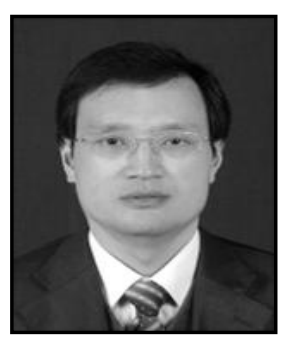

Hongguo Sun. He received his B.E. in Electronic Engineering (1991) from Southeast University and his M.S. in power Electronic (2002) from Nanjing University of Aeronautics \& Astronautics. Now he is associate professor of electrician at School of Electrical Engineering, Yancheng Institute of Technology. His current research interests include different aspects of Power electronics and Microcomputer application. 